\title{
Thermally stimulated luminescence studies of undoped and doped $\mathrm{CaB}_{4} \mathrm{O}_{7}$ compounds
}

\author{
J. Manam*, S.K. Sharma \\ Department of Applied Physics, Indian School of Mines, Dhanbad-826004, India \\ *Corresponding author: Phone: +91 326 2202671, Fax: +91326 2210028, E-mail: jairam_manam@yahoo.co.in
}

\begin{abstract}
Thermoluminescence of undoped and doped $\mathrm{CaB}_{4} \mathrm{O}_{7}$ with activators such as $\mathrm{Cu}$ and $\mathrm{Mn}$ has been investigated. The polycrystalline samples of undoped and doped $\mathrm{CaB}_{4} \mathrm{O}_{7}$ are prepared by melting method. The formation of $\mathrm{CaB}_{4} \mathrm{O}_{7}$ compound is checked by X-ray diffraction study and the compound is found to have orthorhombic structure at room temperature. The TSL studies of undoped $\mathrm{CaB}_{4} \mathrm{O}_{7}$ sample shows two glow peaks at $150^{\circ} \mathrm{C}$ and $265^{\circ} \mathrm{C}$ and one shoulder at around $190^{\circ} \mathrm{C}$. The TSL studies of $\mathrm{Cu}$ doped $\mathrm{CaB}_{4} \mathrm{O}_{7}$ sample also shows two glow peaks at $160^{\circ} \mathrm{C}$ and $270^{\circ} \mathrm{C}$ and a shoulder at around $230^{\circ} \mathrm{C}$ whereas the TSL glow curves of $\mathrm{Mn}$ doped $\mathrm{CaB}_{4} \mathrm{O}_{7}$ has only one single strong glow peak at $135^{\circ} \mathrm{C}$. A comparative TSL studies of these compounds shows that $\mathrm{CaB}_{4} \mathrm{O}_{7}$ compound doped with $\mathrm{Mn}$ is the most sensitive and the TSL intensity is enhanced by about 40 times when compared with the TSL intensity of undoped $\mathrm{CaB}_{4} \mathrm{O}_{7}$ compound. The trap parameters namely order of kinetics $(b)$, activation energy $(E)$ and frequency factor $(s)$ associated with the $135^{\circ} \mathrm{C}$ glow peak of $\mathrm{CaB}_{4} \mathrm{O}_{7}$ : $\mathrm{Mn}$ phosphor are determined using isothermal decay and glow curve shape (Chen's) methods.
\end{abstract}

Keywords: Calcium borate, X-ray diffraction, thermally stimulated luminescence, trap parameters.

Paper received 08.09.03; accepted for publication 11.12.03.

\section{Introduction}

Phosphors prepared from inorganic compounds by doping with suitable activator and coactivator impurities are generally polycrystalline which are capable of converting one or more forms of energy into radiation in or close to the visible region of the electromagnetic spectrum. These phosphors find many industrial applications in the manufacture of TV/CRO screens, fluorescent lamps, EL panels, visible light emitting diodes, X-ray imaging, IR sensors, radiation dosimetry, luminescence paints etc. In recent years, significant progress has been made in the development of new materials for radiation dosimetry. These include alkali and alkaline earth tetra borates $[1,2]$. The following work is undertaken to study the TL mechanism in undoped and doped calcium borate compounds. Thermoluminescence in irradiated sintered $\mathrm{CaB}_{4} \mathrm{O}_{7}$ containing activators such as $\mathrm{Cu}, \mathrm{Pb}, \mathrm{Eu}$ or $\mathrm{Dy}$ has been first investigated by Fukuda et al $[3,4,5]$. As the TL glow curves often depend on the activators so it seems interesting to investigate further the effects of other activator such as $\mathrm{Mn}$ on the TSL output of polycrystalline $\mathrm{CaB}_{4} \mathrm{O}_{7}$ compound.

\section{Experimental details}

The polycrystalline samples of undoped and doped $\mathrm{CaB}_{4} \mathrm{O}_{7}$ were prepared by melting method [6]. The preparation of calcium borate sample has been made by mixing calcium carbonate ( $99 \%$,Loba Chemie, Bombay) and boric acid $(99.5 \%$, s.d. fine-chem Ltd., Boisar ) in stoichiometric ratio and the mixture is melted at $900^{\circ} \mathrm{C}$ in a platinum crucible for 4.5 hours and then cooled at a rate of about $60 \mathrm{~K} / \mathrm{min}$. The crystalline material was ground and sieved to a grain size of $200 \mu \mathrm{m}$. Doped $\mathrm{CaB}_{4} \mathrm{O}_{7}$ samples are prepared in a similar manner by taking the starting material in stoichiometric ratio and adding $0.5 \mathrm{wt} \%$ of $\mathrm{CuCl}_{2}$ ( $98 \%$, Loba Chemie, Bombay) or $\mathrm{MnCl}_{2}$ $(99.5 \%$, s.d. fine-chem Ltd.,Boisar ) in the mixture.

The characterization of $\mathrm{CaB}_{4} \mathrm{O}_{7}$ is carried out by $\mathrm{X}$ ray diffraction study. X-ray diffractogram of the compound is taken at room temperature in a wide range of Bragg angle $2 \theta\left(10^{\circ} \leq 2 \theta \leq 80^{\circ}\right)$ using a X-ray diffractometer type PW 1710, Holland with Cu target and at a scanning rate of $3 \% \mathrm{~min}$.

All samples were heated to $400^{\circ} \mathrm{C}$ for 10 minutes and then quenched to room temperature before $\mathrm{X}$-irradiating 
them. The powder samples were irradiated by X-rays obtained from $\mathrm{Cu}$ target of Machlett tube operated at $20 \mathrm{kV}$ and $15 \mathrm{~mA}$. The TSL studies were made by using Personal Computer Based Thermoluminescence Analyzer System (type 1007) supplied by Nucleonix Systems Private Limited, Hyderabad, India. The glow curves were recorded by heating the samples at a uniform rate of $4^{\circ} \mathrm{C} / \mathrm{s}$ with the help of a temperature controller (type 575) made by Nucleonix Systems Private Limited, Hyderabad, India and the luminescence emission was detected by a photo-multiplier tube (type 9924 B) imported from U.K. The photo-current from PM tube is amplified by a DC amplifier (type 552) made by Nucleonix Systems Private Limited, Hyderabad, India which is interfaced to a personal computer. The T S L out put is finally recorded by a printer connected to the personal computer.

\section{Results and discussion}

\subsection{Structural study}

In order to ascertain the structure of prepared $\mathrm{CaB}_{4} \mathrm{O}_{7}$ compound, X-ray diffraction pattern of powder sample $\mathrm{CaB}_{4} \mathrm{O}_{7}$ is recorded (Fig. 1). The sharp and single diffraction peaks of the XRD pattern suggested the formation of new compound. From the $2 \theta$ values of the diffraction lines, interplanar spacing $(d)$ of the peaks was calculated. The diffraction lines were indexed using a computer program package "Powdmult" [7,8]. Out of those a suitable orthorhombic unit cell was selected for which $\Sigma \Delta d\left(=d_{o b s}-d_{c a l}\right)$ was found to be minimum. The lattice parameters of the unit cell were refined using least-squares method and were found to be: $a=27.9159 \AA, b=3.4790 \AA$, $c=6.4198 \AA$. A good agreement between the observed and calculated d-values (Table 1) suggests the suitability of the crystal structure and unit cell parameters.

Table 1. Comparison of observed and calculated d-values ( $($ ) of some reflections of $\mathrm{CaB}_{4} \mathrm{O}_{7}$ sample at room temperature.

\begin{tabular}{cccccc}
\hline \hline$h$ & $k$ & $l$ & $d_{\text {obs }}$ & $d_{c a l}$ & $I / I_{0} * 100$ \\
\hline 1 & 1 & 0 & 3.4531 & 3.4522 & 44 \\
0 & 2 & 0 & 1.7399 & 1.7395 & 19 \\
0 & 0 & 4 & 1.6053 & 1.6050 & 25 \\
8 & 2 & 0 & 1.5559 & 1.5568 & 100 \\
3 & 2 & 2 & 1.5100 & 1.5091 & 14 \\
19 & 0 & 1 & 1.4308 & 1.4302 & 16 \\
7 & 1 & 4 & 1.3680 & 1.3688 & 15 \\
11 & 2 & 3 & 1.1919 & 1.1971 & 9 \\
0 & 3 & 1 & 1.1411 & 1.1412 & 14 \\
4 & 0 & 6 & 1.0575 & 1.0576 & 15 \\
14 & 2 & 4 & 1.0153 & 1.0151 & 15 \\
27 & 1 & 2 & 0.9469 & 0.9470 & 6 \\
30 & 1 & 0 & 0.8989 & 0.8989 & 5 \\
28 & 1 & 3 & 0.8747 & 0.8747 & 12 \\
\hline \hline
\end{tabular}

\subsection{TSL study}

Under this study, glow curves of undoped, $\mathrm{Cu}$ and $\mathrm{Mn}$ doped $\mathrm{CaB}_{4} \mathrm{O}_{7}$ samples are recorded for the different time of X-irradiation.

The TSL glow curves of $\mathrm{CaB}_{4} \mathrm{O}_{7}$ powder samples are recorded by $\mathrm{X}$-irradiating at room temperature for 1, 2, 4 and 10 minutes (Fig. 2). The room temperature $\mathrm{X}$-irradiated $\mathrm{CaB}_{4} \mathrm{O}_{7}$ sample exhibit two glow peaks at temperatures 150 and $265^{\circ} \mathrm{C}$ and one shoulder at around $190^{\circ} \mathrm{C}$ and the intensity of $150^{\circ} \mathrm{C}$ glow peak is the stronger. Moreover the intensities of the glow peaks are found to increase with increase of the X-ray dose. The TSL glow curves of $\mathrm{Cu}$-doped $\mathrm{CaB}_{4} \mathrm{O}_{7}$ powder sample are recorded by $\mathrm{X}$-irradiating at room temperature for 1, 3 and 5 minutes (Fig. 3). The T S L glow curves of Xirradiated $\mathrm{CaB}_{4} \mathrm{O}_{7}: \mathrm{Cu}$ exhibit two glow peaks at 160 and $270^{\circ} \mathrm{C}$ and one shoulder at around $230^{\circ} \mathrm{C}$ and the intensity of $160^{\circ} \mathrm{C}$ glow peak is the higher. In this case also the intensities of glow peaks are found to increase with the increase of X-ray dose. The TSL glow curves of $\mathrm{Mn}$ doped $\mathrm{CaB}_{4} \mathrm{O}_{7}$ powder sample are recorded by $\mathrm{X}$ irradiating at room temperature for 10,20,30,45 and 60 seconds (Fig. 4). The TSL glow curves of X-irradiated $\mathrm{CaB}_{4} \mathrm{O}_{7}: \mathrm{Mn}$ exhibit only one strong TL glow peak at the temperature of $135^{\circ} \mathrm{C}$. It is observed that in this case also, the glow peaks grow in intensities with the increase of X-ray dose.

The TL glow curves of both undoped and $\mathrm{Cu}$ doped $\mathrm{CaB}_{4} \mathrm{O}_{7}$ compounds shows two glow peaks indicating that two different species of traps are being activated within the particular temperature range each with its own value

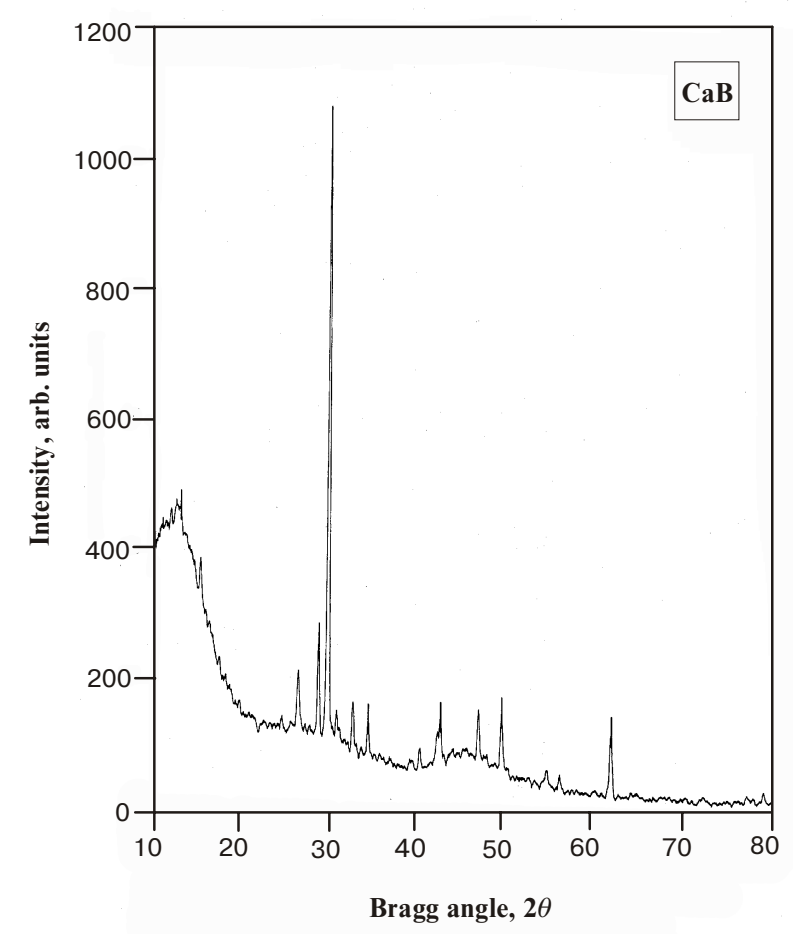

Fig. 1. XRD pattern of $\mathrm{CaB}_{4} \mathrm{O}_{7}$ sample at room temperature. 


\section{J. Manam, S.K. Sharma: Thermally stimulated luminescence studies of undoped ...}

of activation energy $(E)$ and frequency factor $(s)$. Comparison of intensities of glow peaks (Fig. 5) shows that addition of $\mathrm{Cu}$ impurity to undoped $\mathrm{CaB}_{4} \mathrm{O}_{7}$ enhance the TL intensity by a very small amount.

The $\mathrm{Mn}$ doped $\mathrm{CaB}_{4} \mathrm{O}_{7}$ compound shows only one single strong TL glow peak indicating that only one species of traps are being activated at a particular temperature with its activation energy $(E)$ and frequency factor $(s)$. Moreover this glow peak is observed at some low temperature compared to undoped and $\mathrm{Cu}$ doped $\mathrm{CaB}_{4} \mathrm{O}_{7}$ compounds. Comparison of intensity of glow peak (Fig. 5)

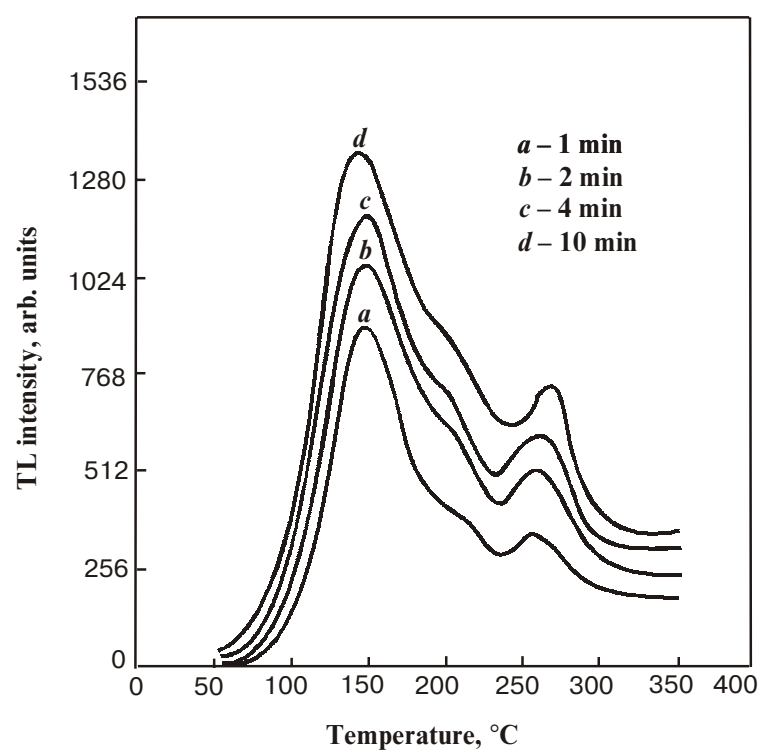

Fig. 2. TSL glow curves of $\mathrm{CaB}_{4} \mathrm{O}_{7}$ sample for different times of $\mathrm{X}$-irradiation.

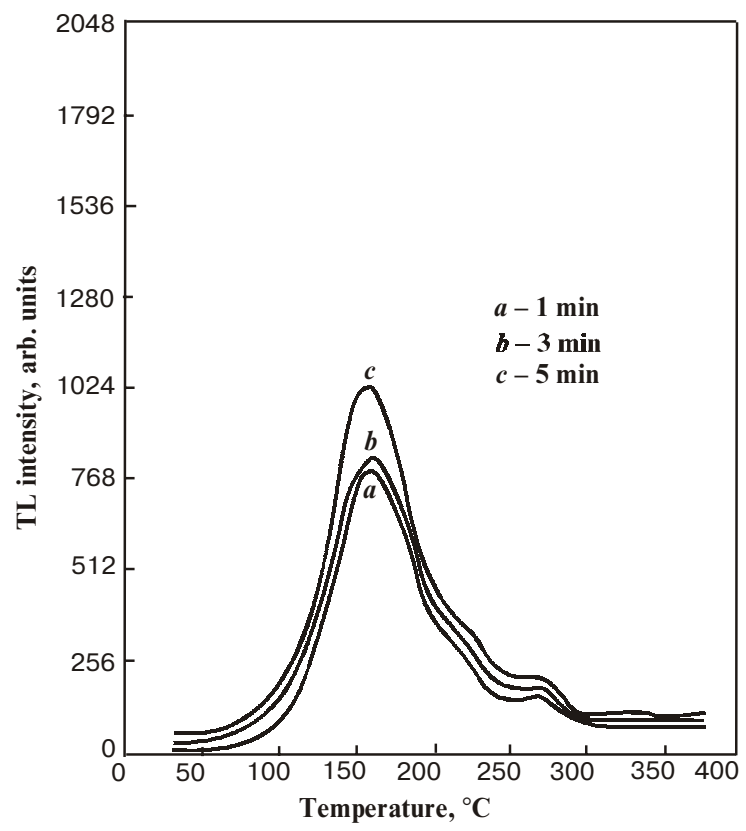

Fig. 3. TSL Glow curves of $\mathrm{CaB}_{4} \mathrm{O}_{7}$ : $\mathrm{Cu}$ sample for different times of X-irradiation. in $\mathrm{Mn}$ doped $\mathrm{CaB}_{4} \mathrm{O}_{7}$ compound shows that addition of $\mathrm{Mn}$ impurity to undoped $\mathrm{CaB}_{4} \mathrm{O}_{7}$ compound enhances the TL intensity by about 40 times.

It has been suggested that glow peak observed at $135^{\circ} \mathrm{C}$ in $\mathrm{CaB}_{4} \mathrm{O}_{7}: \mathrm{Mn}$ is peculiar to $\mathrm{Mn}$ activator and is related to the relaxation of the excited $\mathrm{Mn}^{++}$ions. Upon irradiation, $\mathrm{Mn}^{++}$ions capture one or two electrons to become $\mathrm{Mn}^{+}$or $\mathrm{Mn}^{0}$.

$$
\begin{aligned}
& \mathrm{Mn}^{++}+\text {electron } \rightarrow \mathrm{Mn}^{+} \\
& \mathrm{Mn}^{++}+2 \text { electron } \rightarrow \mathrm{Mn}^{0}
\end{aligned}
$$

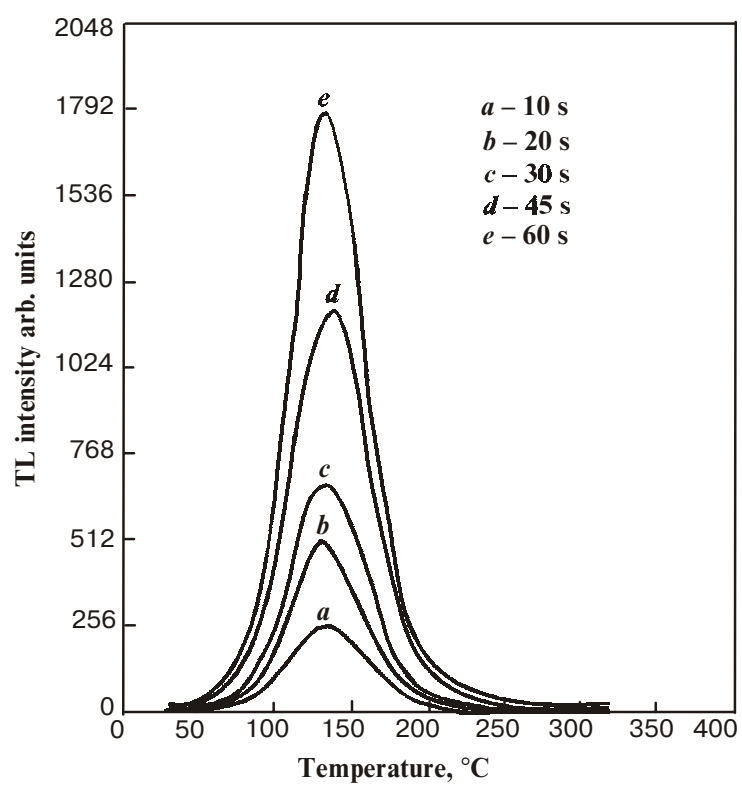

Fig. 4. TSL glow curves of $\mathrm{CaB}_{4} \mathrm{O}_{7}: \mathrm{Mn}$ sample for different times of X-irradiation.

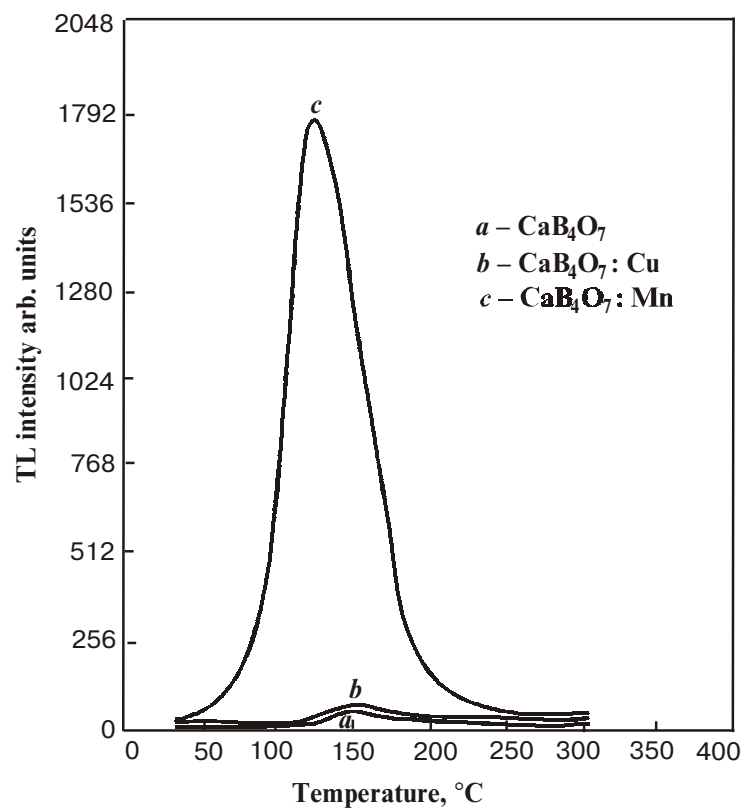

Fig. 5. Comparative TSL glow curves of undoped $\mathrm{Cu}$ and $\mathrm{Mn}$ doped culcium borate samples. 


\section{J. Manam, S.K. Sharma: Thermally stimulated luminescence studies of undoped ...}

On thermal stimulation, $\mathrm{Mn}^{+}$ions give rise to TSL emission according to the following mechanism:

$\mathrm{Mn}^{+}+$hole $\rightarrow\left(\mathrm{Mn}^{++}\right)^{*} \rightarrow \mathrm{Mn}^{++}+h v$.

Whereas in case of $\mathrm{Mn}^{0}$ atoms, thermal stimulation gives rise to TSL emission according to the following mechanism:

$\mathrm{Mn}^{0}+2$ hole $\rightarrow\left(\mathrm{Mn}^{++}\right)^{*} \rightarrow \mathrm{Mn}^{++}+h v$

The increase in the intensities of the glow curves with increase of irradiation dose can be understood by the fact that more and more traps responsible for these glow peaks were getting filled with the increase of irradiation dose and subsequently these traps release the charge carriers on thermal stimulation to finally recombine with their counterparts, thus giving rise to different glow peaks.

\subsection{Trap parameters}

Trap parameters such as order of kinetics (b), activation energy $(E)$ and frequency factor $(s)$ are calculated for the $135^{\circ} \mathrm{C}$ glow peak of $\mathrm{CaB}_{4} \mathrm{O}_{7}: \mathrm{Mn}$ phosphor using the isothermal luminescence decay method (ILDM). The theory and experimental details of the method is described elsewhere [9]. As a check the trap parameters are also calculated by the glow curve shape (Chen's) method.

\subsubsection{Isothermal luminescence decay method}

The isothermal luminescence decay method is based on recording the decay of luminescence intensity with respect to time at a constant temperature. Three temperatures are chosen on the rising side of the glow peak whose trapping parameters are to be determined. After irradiating the sample by X-ray or $\gamma$-ray of suitable dose, it is heated to one of the chosen temperatures and decay of luminescence intensity is recorded at a constant temperature. This procedure is repeated for other two temperatures. The experimental data is tested for finding the order of kinetics.

\section{First order kinetics}

TL intensity equation for the first order kinetics is [9]:

$$
I=-\left(\frac{d n}{d t}\right)=n s \exp \left(-\frac{E}{k T}\right) \text {. }
$$

The solution of intensity equation for the isothermal case :

$$
I(t)=n_{0} s \exp \left(-\frac{E}{k T}\right) \exp \left[-s t \exp \left(-\frac{E}{k T}\right)\right]
$$

or,

$$
\ln [I(t)]=-\left[s \exp \left(-\frac{E}{k T}\right)\right] t+\left[\ln \left(n_{0} s\right)-\frac{E}{k T}\right]
$$

So for the first order case, plot of $\ln [I(t)]$ vs time should yield a straight line.

The slope of this straight line is:

$m=s \exp \left(-\frac{E}{k T}\right)$

or,

$\ln [m(T)]=-\frac{E}{k T}+\ln (s)$

The slope (m) of straight line plots of $\ln [I(t)]$ vs time at different temperatures are noted and again $\ln [m(T)]$ vs $1 / T$ are plotted which is a straight line (equ.2). The slope $m^{\prime}=-E / k$ of this straight line give thermal activation energy $(E)$ where $\mathrm{k}$ is the Boltzman's constant and intercept part $\ln (s)$ of equation (2) gives the value of frequency factor $(s)$.

\section{General order kinetics}

TL intensity equation for the general order kinetics is:

$I=-\left(\frac{d n}{d t}\right)=s^{\prime} n^{b} \exp \left(-\frac{E}{k T}\right)$,

where $s^{\prime}=\frac{s}{n_{0}^{b-1}}$ is the pre-exponential factor.

The solution of intensity equation for the isothermal case [10]:

$\left(\frac{I_{0}}{I}\right)^{\frac{b-1}{b}}-1=s \exp \left[-\frac{E}{k T}\right](b-1) t$,

so for the general order case, plot of $\left(I_{0} / I\right)^{(b-1) / b}-1$ vs time should yield a straight line where $b$ is the order of kinetics $(1<b \leq 2), I_{0}$ is the intensity at $t=0$ and $I$ is the intensity at any instant $t$. The experimental data is tested by choosing different test values of $b$, among which the value of $b$ that gives the best fit as straight line gives the order of kinetics $(b)$.

The slope of this straight line equation (3) is:

$m=(b-1) s \exp \left(-\frac{E}{k T}\right)$.

The determination of slope $(m)$ of straight line plots of $\left(I_{0} / I\right)^{(b-1) / b}-1$ vs time at different temperatures will give the value of frequency factor according to the relation :

$$
s=\frac{\left(m_{2}\right) \frac{T_{2}}{T_{2}-T_{1}}}{(b-1)\left(m_{1}\right) \frac{T_{1}}{T_{2}-T_{1}}},
$$

where $m_{1}$ and $m_{2}$ are the slopes corresponding to the temperatures $T_{1}$ and $T_{2}$ respectively.

From equation (4):

$$
\ln [m(T)]=-\frac{E}{k T}+\ln [s(b-1)] \text {. }
$$




\section{J. Manam, S.K. Sharma: Thermally stimulated luminescence studies of undoped ...}

Now to find the thermal activation energy $(E)$ a graph $\ln [m(T)]$ vs $1 / T$ is plotted, which is a straight line (equation 6). The slope $m^{\prime}=-E / k$ of this straight line graph will give the value of thermal activation energy $(E)$.

In order to calculate the trapping parameters corresponding to $135^{\circ} \mathrm{C}$ glow peak, three temperatures namely 120,125 and $130^{\circ} \mathrm{C}$ were chosen and decay of luminescence intensity with time at these temperatures were recorded by $\mathrm{X}$-irradiating the sample for 1 minute. The plots of $\ln I$ vs time were drawn at these temperatures which do not fit into the straight line nature which establish that the glow peak at $135^{\circ} \mathrm{C}$ does not obey first order kinetics. This indicates that TSL mechanism at this temperature is not associated with first order kinetics. Then plots of $\left(I_{0} / I\right)^{(b-1) / b}-1$ vs time were drawn for different values of $b$ $(1<b \leq 2)$. The best straight line fitting is obtained for $b=2$ as shown in Fig. 6. This established that $135^{\circ} \mathrm{C}$ glow peak is associated with second order kinetics. The value of frequency factor $(s)$ is found from the slope of these straight lines at 120 and $125^{\circ} \mathrm{C}$ by using the equation (5) and is found to be $4.68 \times 10^{9} \mathrm{sec}^{-1}$. To find the thermal activation energy $(E)$, the slope $(\mathrm{m})$ of these straight lines for the temperatures 120,125 and $130^{\circ} \mathrm{C}$ were noted and were plotted as $\ln (m)$ vs $1 / T$ as shown in Fig. 7 which is a straight line as expected. The activa-

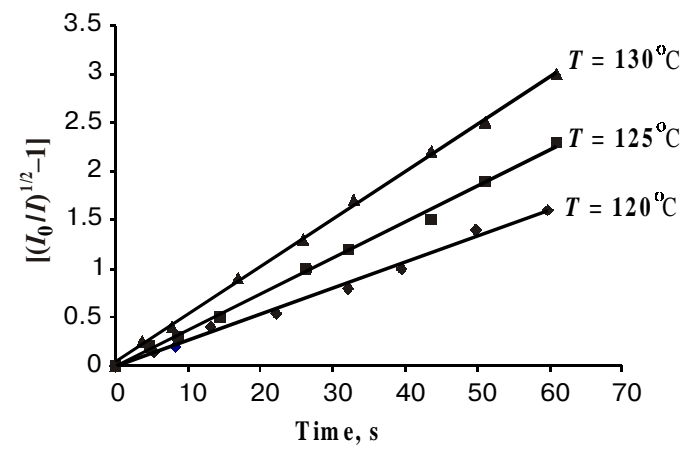

Fig. 6. Isothermal luminescence decay curves of $\mathrm{CaB}_{4} \mathrm{O}_{7}: \mathrm{Mn}$ sample for $135^{\circ} \mathrm{C}$ glow peak.

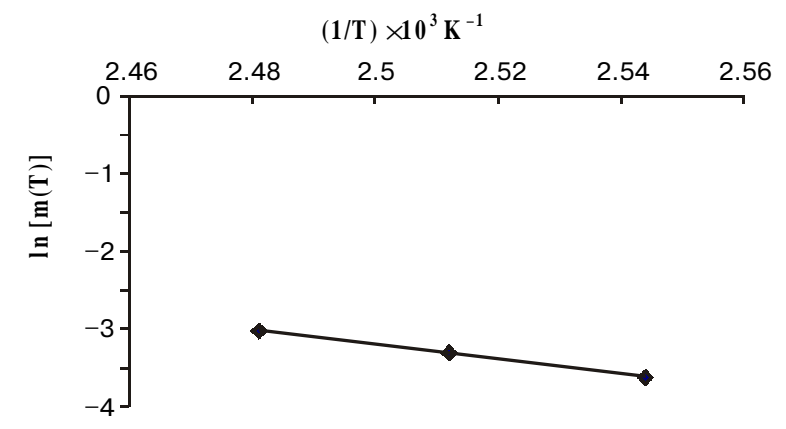

Fig. 7. Plot of $\ln [m(T)]$ vs $1 / T$ for $135^{\circ} \mathrm{C}$ glow peak of $\mathrm{CaB}_{4} \mathrm{O}_{7}: \mathrm{Mn}$ sample. tion energy $(E)$ is calculated from the slope $\left(m^{\prime}=-E / k\right)$ of this straight line and is found to be $0.82 \mathrm{eV}$.

\subsubsection{Glow curve shape method}

The method based on the shape of glow curve proposed by Chen was used to verify the above calculated trapping parameters. To determine these parameters the following shape parameters are determined: the total half intensity width $\left(\omega=T_{2}-T_{1}\right)$, the high temp. half width ( $\left.\delta=T_{2}-T_{m}\right)$, the low temp. half width $\left(\tau=T_{m}-\mathrm{T}_{1}\right)$, where $T_{m}$ is the peak temperature and $T_{1}$ and $T_{2}$ are temp. on either side of $T_{m}$ corresponding to half peak intensity.

Order of kinetics :

Order of kinetics $(b)$ is determined by calculating the symmetry factor $\left(\mu_{g}\right)$ of the glow peak from the known values of shape parameters :

$\mu_{g}=\frac{\delta}{\omega}=\frac{T_{2}-T_{m}}{T_{2}-T_{1}}$.

The shape factor $\left(\mu_{g}\right)$ for the $135^{\circ} \mathrm{C}$ glow peak of $\mathrm{CaB}_{4} \mathrm{O}_{7}: \mathrm{Mn}$ is found to be 0.52 which suggest that this peak obey second order kinetics.

Activation energy :

Activation energy $(E)$ is calculated by using the Chen's equations which gives the trap depth in terms of $\tau, \delta, \omega$. A general formula for $E$ was given by:

$$
E=\frac{c_{\gamma} k T_{m}^{2}}{\gamma}-b_{\gamma} 2 k T_{m},
$$

where $\gamma$ is $\tau, \delta$ or $\omega$. The constants $c_{\gamma}$ and $b_{\gamma}$ for the three equations ( $\tau, \delta$ and $\omega$ ) and for second order kinetics are $C_{\tau}=1.81, b_{\tau}=2.0, C_{\delta}=1.71, b_{\delta}=0, C_{\omega}=3.54, b_{\omega}=1.0$.

The activation energy for the $135^{\circ} \mathrm{C}$ glow peak of $\mathrm{CaB}_{4} \mathrm{O}_{7}$ : Mn when calculated by equation (8) using low temp. half width, high temp. half width and full width of the peak at its half height are found to be $0.81 \mathrm{eV}, 0.83 \mathrm{eV}$ and $0.82 \mathrm{eV}$ giving mean value of activation energy $0.82 \mathrm{eV}$.

Frequency factor :

Once order of kinetics and activation energy are determined, the frequency factor $(s)$ can be calculated by the equation given by Chen $\&$ Winer :

$\frac{q E}{k T_{m}^{2}}=s\left[1+(b-1) \frac{2 k T_{m}}{E}\right] \exp \left(-\frac{E}{k T_{m}}\right)$

where $q$ is the heating rate.

The frequency factor for the $135^{\circ} \mathrm{C}$ glow peak of $\mathrm{CaB}_{4} \mathrm{O}_{7}$ : Mn when calculated by using equation (9) is found to be $2.96 \times 10^{9} \mathrm{sec}^{-1}$.

Table 2 gives the values of trapping parameters of the $135^{\circ} \mathrm{C}$ glow peak of $\mathrm{CaB}_{4} \mathrm{O}_{7}: \mathrm{Mn}$ phosphor calculated by isothermal decay and Chen's methods. The results shows a very good agreement between the trapping parameters calculated by the two methods and indicates 
J. Manam, S.K. Sharma: Thermally stimulated luminescence studies of undoped ...

Table 2. Trap parameters of $135^{\circ} \mathrm{C}$ glow peak of $\mathrm{CaB}_{4} \mathrm{O}_{7}$ : Mn phosphor.

\begin{tabular}{|l|c|c|}
\hline \multirow{2}{*}{ Trap parameters } & \multicolumn{2}{|c|}{ Method } \\
\cline { 2 - 3 } & $\begin{array}{c}\text { Isothermal } \\
\text { decay }\end{array}$ & Chen's \\
\hline Order of kinetics & 2 & 2 \\
Activation energy $(E)$ in eV & 0.82 & 0.82 \\
Frequency factor $(s)$ in s $^{-1}$ & $4.68 \times 10^{9}$ & $2.96 \times 10^{9}$ \\
\hline \hline
\end{tabular}

the reliability of two methods and accuracy of the measurement of parameters.

\section{Conclusions}

(i) The compound $\mathrm{CaB}_{4} \mathrm{O}_{7}$ has orthorhombic structure at room temperature.

(ii) The addition of $\mathrm{Mn}$ impurity to undoped $\mathrm{CaB}_{4} \mathrm{O}_{7}$ enhances the TL intensity by about 40 times.

(iii) The $135^{\circ} \mathrm{C}$ glow peak of $\mathrm{CaB}_{4} \mathrm{O}_{7}$ : Mn phosphor is due to the second order kinetics with the activation energy $0.82 \mathrm{eV}$ and frequency factor $4.68 \times 10^{9} \mathrm{~s}^{-1}$.

\section{References}

1. J. Manam, A.K. Singh and S.K. Sharma, Thermally stimulated luminescence studies of undoped, $\mathrm{Cu}$ and $\mathrm{Mn}$ doped lithium borate compounds // Ind. J. Phys., 76A (6) pp. 549$552(2002)$

2. J. Manam and S.K. Sharma, Thermally stimulated luminescence studies of undoped, $\mathrm{Cu}$ and $\mathrm{Mn}$ doped magnesium borate compounds // Asian J. Phys. 12(4) (2003) (In Press).

3. Y. Fukuda, A. Tomita and N. Takeuchi, Thermoluminescence and thermally stimulated exoelectron emission in glass and sintered $\mathrm{CaB}_{4} \mathrm{O}_{7}: \mathrm{Cucl}_{2} / /$ Phys. Stat. Sol. (a) 85, pp. K141K144 (1984).

4. Y. Fukuda, A. Tomita and N. Takeuchi, Thermoluminescence and thermally stimulated exoelectron emission of sintered $\mathrm{CaB}_{4} \mathrm{O}_{7}$ doped with $\mathrm{Pb}$, Eu or Dy // Phys. Stat. Sol.(a) 99 pp. K135-K138 (1987).

5. Y. Fukuda, K. Mizuguchi and N. Takeuchi, Thermoluminescence in sintered $\mathrm{CaB}_{4} \mathrm{O}_{7}$ : Dy and $\mathrm{CaB}_{4} \mathrm{O}_{7}: \mathrm{Eu} / /$ Radiat. Prot. Dosim. 17 pp. 397-401 (1986).

6. J. Azorin, C. Furetta and A. Scacco, Preparation and properties of thermoluminescent materials // Phys. Stat. Sol. (a) 138 pp. 9-46 (1993).

7. R.N.P. Choudhary, R. Palai and S. Sharma, Structural, dielectric and electrical properties of lead cadmium tungstate ceramics // Mater. Sci. and Engg. B77, pp. 235-240 (2000).

8. T. Kar and R.N.P. Choudhary, Structural, dielectric and electrical conducting properties of KB'B' $\mathrm{O}_{6}\left(\mathrm{~B}^{\prime}=\mathrm{Nb}, \mathrm{Ta}\right.$; B" = W, Mo) ceramics // J. of Phys. \& Chem. of Solids 62 pp. 1149-1161 (2001)

9. R. Chen and S.W.S. McKeever, Theory of Thermoluminescence and Related Phenomena, World Scientific, Singapore (1997).

10. J. Manam, Variation of order of kinetics with dose of Xirradiation in LiF single crystals // Ind. J. Phys. 68A (1) pp. 105-112 (1994). 